\title{
DESIGN, STATUS, AND FIRST OPERATIONS OF THE SPALLATION NEUTRON SOURCE POLYPHASE RESONANT CONVERTER MODULATOR SYSTEM*
}

\author{
W. A. Reass, S. E. Apgar, D. M. Baca, J. D. Doss, J. M. Gonzales, R. F. Gribble, T. W. Hardek, \\ M. T. Lynch, D. E. Rees, P. J. Tallerico, and P. G. Trujillo \\ Los Alamos National Laboratory, P.O. Box 1663, Los Alamos, NM 87545, USA \\ And \\ D. E. Anderson, D. A. Heidenreich, J. D. Hicks, and V. N. Leontiev Oak Ridge National \\ Laboratory, P.O. Box 2001, Oak Ridge, TN 37831, USA
}

\section{Abstract}

The Spallation Neutron Source (SNS) is a new $1.4 \mathrm{MW}$ average power beam, $1 \mathrm{GeV}$ accelerator being built at Oak Ridge National Laboratory. The accelerator requires 15 converter-modulator stations each providing between 9 and $11 \mathrm{MW}$ pulses with up to a $1.1 \mathrm{MW}$ average power. The converter-modulator can be described as a resonant $20 \mathrm{kHz}$ polyphase boost inverter. Each converter modulator derives its buss voltage from a standard substation cast-core transformer. Each substation is followed by an SCR pre-regulator to accommodate voltage changes from no load to full load, in addition to providing a soft-start function. Energy storage is provided by self-clearing metallized hazy polypropylene traction capacitors. These capacitors do not fail short, but clear any internal anomaly. Three "H-Bridge" IGBT transistor networks are used to generate the polyphase $20 \mathrm{kHz}$ transformer primary drive waveforms. The $20 \mathrm{kHz}$ drive waveforms are time-gated to generate the desired klystron pulse width. Pulse width modulation of the individual 20 $\mathrm{kHz}$ pulses is utilized to provide regulated output waveforms with DSP based adaptive feedforward and feedback techniques. The boost transformer design utilizes nanocrystalline alloy that provides low core loss at design flux levels and switching frequencies. Capacitors are used on the transformer secondary networks to resonate the leakage inductance. The transformers are wound for a specific leakage inductance, not turns ratio. This design technique generates multiple secondary volts per turn as compared to the primary. With the appropriate tuning conditions, switching losses are minimized. The resonant topology has the added benefit of being deQed in a klystron fault condition, with little energy deposited in the arc. This obviates the need of crowbars or other related networks. A review of these design parameters, operational performance, production status, and ORNL installation and performance to date will be presented.

\section{HARDWARE DESIGN}

The system block diagram of the SNS convertermodulator is shown in Figure 1. This depicts a standard vacuum cast-core transformer substation followed by an SCR controller for DC voltage regulation. The convertermodulator follows with the self-healing capacitor energy storage bank. The fabrication of the converter-modulator systems is accomplished through industrial fabrication contracts for the four major subsystems, consisting of: A) the utility substation, B) the SCR phase controller, C) the converter-modulator assembly, and D) the equipment control rack. The converter-modulator assembly is a "build-to-print" contract, the others, a "build-tospecification", all awarded to the lowest cost qualifying bidder.

\section{HZ UTILITY SYSTEMS}

The individual converter-modulator substations contain harmonic traps and filters to maintain IEEE 519 and 141 standards within the local distribution network. To maximize substation efficiency $(\sim 99 \%)$, a standard "traction" style vacuum cast core transformer is used along with vacuum cast coils for the traps and filters. Since the unit contains no oil, secondary oil containment,

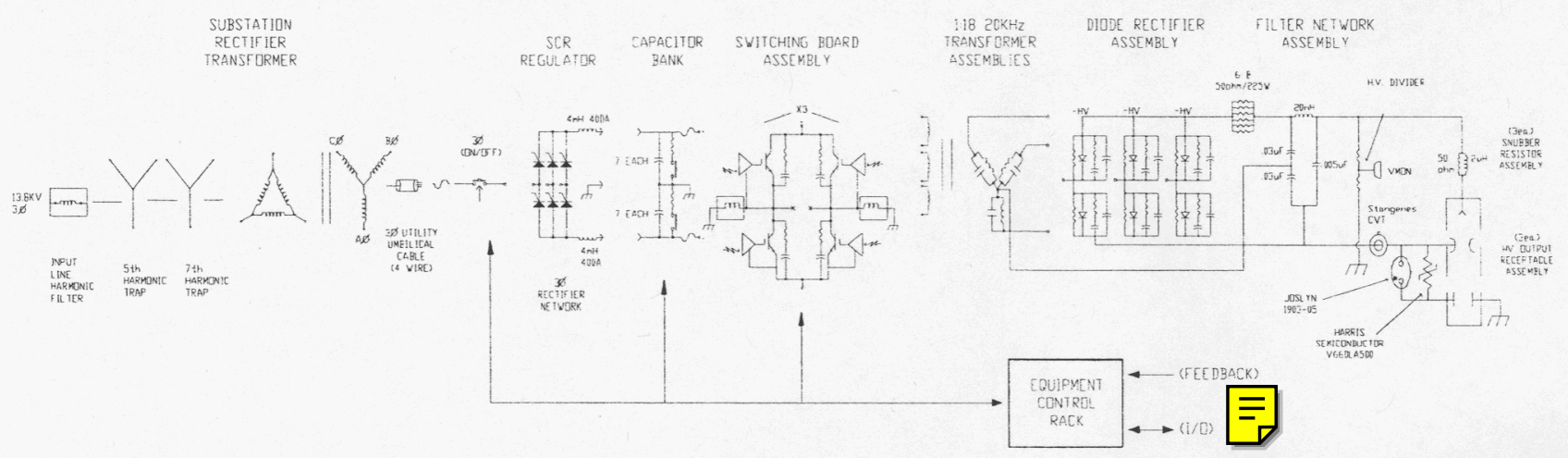

Figure 1: System Block Diagram 
fire suppression equipment, and environmental impact statements are not required. The overall design topology further simplifies installation, a single utility cable pull for the input and output with a lightweight, two-piece, design that can be "forked" into position onto the outdoor pad. To maintain balanced line currents and core flux, the neutral is not grounded. With the repetitive pulsed loading of the transformer, there are no engineering (e.g. harmonic mitigation) or cost advantages to utilize a 6 phase, 12 pulse rectification system. A standard 3 phase system is less expensive and easier to filter. The substations for the SNS Accelerator have been manufactured by Dynapower Corporation located in Burlington, Vermont.

\section{SCR PHASE CONTROLLER}

Each converter-modulator substation is followed by an SCR phase controller, located indoors, in the klystron gallery. A single utility pull using armored triplex between the substation and SCR regulator simplifies the interconnect between the pad and the indoor equipment. The SCR phase controller accommodates incoming line voltage variations resulting from network, transformer, and trap impedances, from no-load to full load. The SCR phase controller also provides the soft-start function and operates at a nominal $+/-1250$ Volt output with a 400 Amp rating. This unit is $99.5 \%$ efficient and has also been manufactured by Dynapower Corporation.

\section{CONVERTER MODULATOR ASSEMBLY}

A view of the completed converter modulator assembly is shown in Figure 2. The oil tank, safety enclosure, and water distribution panel are the prominent features that can be noted in this figure. Dynapower Corporation located in Burlington, Vermont won the contract for the build-to-print converter modulator assembly. The first 4 production converter modylator assemblies have been delivered to ORNL in the $2^{\text {nd }}$ quarter of fiscal year 2003.

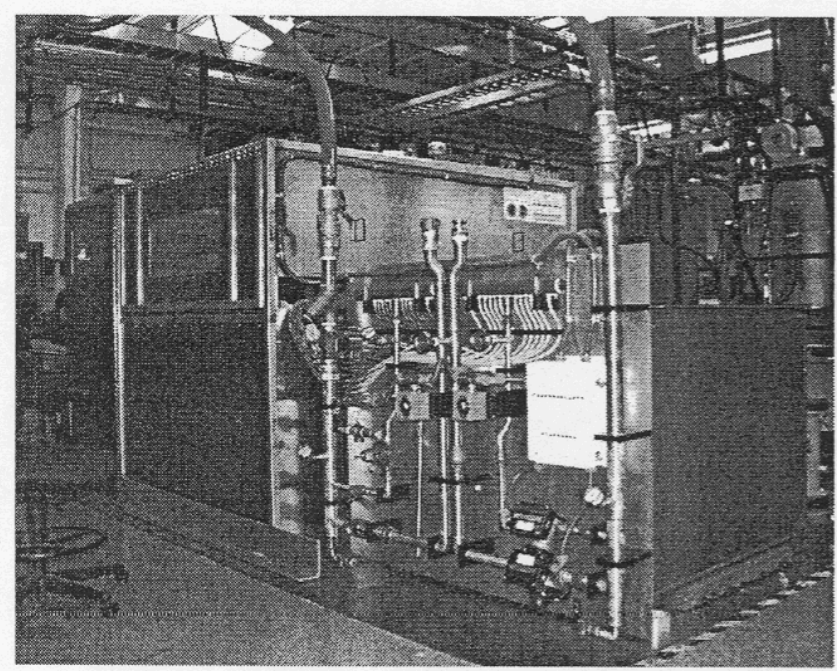

Figure 2: Converter Modulator Assembly

\section{Self-Healing Capacitors}

The energy storage capacitors used for the converter modulator are units similar to those used in traction application. Thomson Passive Components (AVX), located in Saint-Appollinaire, France worked with us to develop a lower inductance capacitor for our high power, $20 \mathrm{kHz}$, switching application. Internal fabrication methodology is optimized to provide enhanced current distribution within the capacitor and also minimize internal interconnect inductance. The all film design provides for excellent energy density and the use of highohm metal electrode deposition ensures good current balance through all the internal foil packs. As in traction applications, our capacitors use the technology of metallized hazy polypropylene dielectrics that do not fail short, but fuse or "clear" any internal anomaly. Also, at our capacitor voltage rating $(1.5 \mathrm{kV})$, there has not been a recorded internal capacitor buss failure. With the converter modulator operation at full output with a maximum bank voltage of $1.25 \mathrm{kV}$, the capacitor lifetime is calculated to be over 300,000 hours, including derating factors. A view of the capacitor racks is shown on the next page in Figure 3. Bank fusing does not seem to reduce physical IGBT failure damage and fusing is not used in the present production design. However, it appears that the fusing can limit "action" in other failure modes and possibly reduce busswork or cabling damage. This is one area we will again examine in future designs.

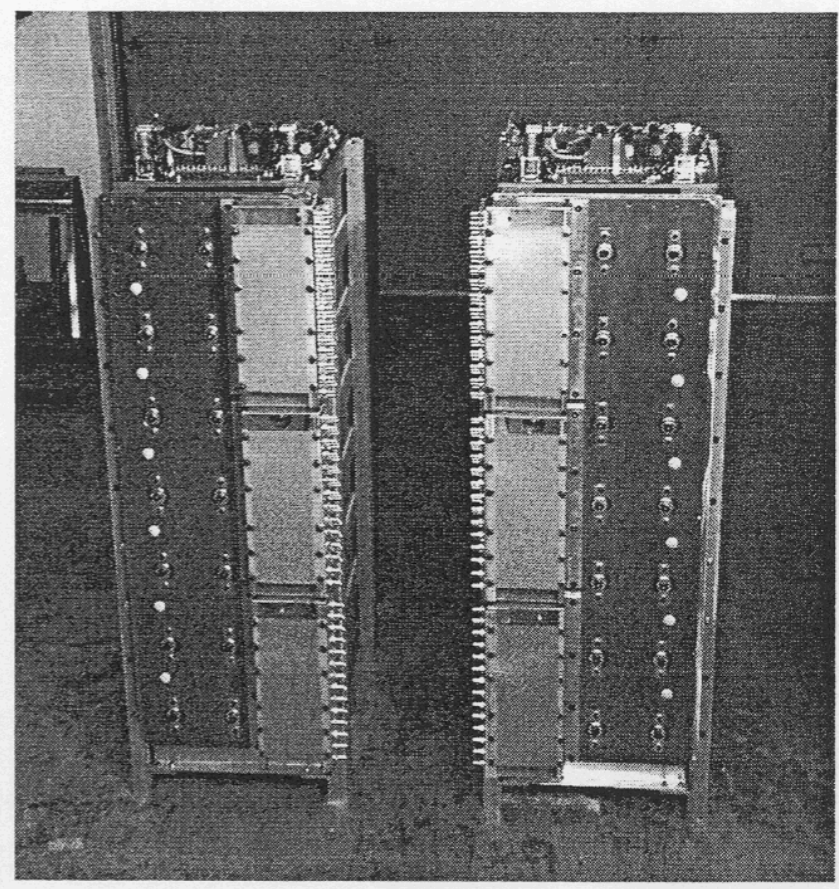

Figure 3: Capacitor Rack Assemblies

\section{IGBT Switch Plate Assembly}

The IGBT switch plate assemblies are designed to be easily removed like a large printed circuit card, such that maintenance and repair can be accommodated off-line. Sliding high-current contacts of multilam louvers interface to the transformer primary busswork, which 
terminate on the modulator tank lid. Each switch plate contains four IGBT's in an "H-bridge" configuration. The IGBT device family is the 3300 Volt, 1200 Ampere devices. The Eupec FZ1200R33KL2 device is being utilized that have an improved "FIT" rate for higher voltage reliability. The mechanical design of the switch plate assembly has the IGBT's terminals directly opposite one-another (face-to-face), to provide a low inductance interconnection methodology. This results in a buss-work rail-to-rail inductance $(\mathrm{V}+$ to $\mathrm{V}-$ ) of $\sim 4 \mathrm{NH}$. This low inductance is necessary for "snubberless" IGBT switching. Low inductance $(\sim 9 \mathrm{nH})$, high frequency IGB'T bypass capacitors for this assembly have been developed by General Atomics Energy Products (formerly Maxwell) and are shown in Figure 4 . The resulting inductance of the IGBT switch plate network of $\sim 7 \mathrm{nH}$ is desirable to minimize overshoot and ringing from the multi-kA 20 $\mathrm{kHz}$ switching that can have dI/dT's of $\sim 10 \mathrm{kA} / \mathrm{uS}$. 'The IGBT switch plate assemblies also must switch the peak power of the system, $11 \mathrm{MW}$, not just the average power. With the high peak powers involved, additional "on board" energy storage is provided by 8 each $10 \mathrm{uF}, 2 \mathrm{kV}$ capacitors, also manufactured by General Atomics Energy Products.

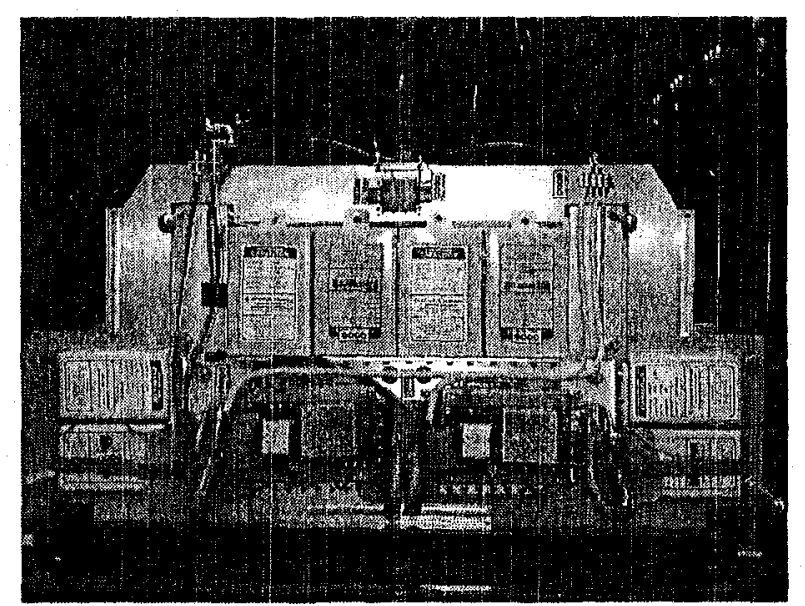

Figure 4: IGBT Switch Plate Assembly

\section{Amorphous Nanocrystalline Boost Transformers}

The development of the amorphous nanocrystalline transformer core was another long lead development for this project. The characteristics of the nano material are given in the following table:

\begin{tabular}{|l|l|}
\hline Mu & 50,000 \\
\hline Lamination Thickness & $0008^{\mathrm{N}}$ \\
\hline Lamination Insulation & \multicolumn{1}{|c|}{ N Namlite } \\
\hline Stacking Factor & $-90 \%$ \\
\hline Bsat & $12.3 \mathrm{kG}$ \\
\hline Core Loss (our use) & $-300 \mathrm{~W}$ \\
\hline Core Weight (our use) & $-95 \mathrm{bs}$ \\
\hline Power (each core) & $330 \mathrm{~kW}$ \\
\hline
\end{tabular}

Table 1: Nano Material Characteristics

The amorphous nanocrystalline material has exceptional performance as a function of frequency and flux density with the added benefit of having "zeromagnetostriction". It does not vibrate or make significant noise with excitation. The windings on the core are wound as two single layer solenoids with a turns ratio of $1: 19$, for the $140 \mathrm{kV}$ output configuration. A view of the nanocrystalline boost transformer is shown in Figure 5. The overall height is about 24 " tall with a total assembly weight of $\sim 150$ lbs. The secondary windings are resonated with peaking capacitors which provide two important functions, (1) an optimized value provides "zero-voltage-switching" for the IGBT's, and (2), the multiple transformer resonant circuits create "polyphase resonant voltage multiplication". The transformers are wound with a ratio of $1: 19$, but the output is about 1:60. Unlike previous power transformers with the same "voltsper-turn" for both the primary and secondary, this design generates multiple volts-per-turn on the secondary. In addition, the core flux expended is that of the primary. It would seem that the secondary leakage inductance isolates the core from the voltage swing generated on the secondary. The zero-voltage-switching characteristic minimizes the IGBT switching loss, turn on is soft without forced commutation (and losses) of the opposite IGBT free-wheeling diode. The transformers are resonated with special peaking capacitors developed by General Atomics Energy Products and circulate many MVAR at $20 \mathrm{kHz}$ with $100 \%$ reversal to $\sim 160 \mathrm{kV} \mathrm{p}-\mathrm{p}$.

\section{Resonant Rectification System}

To provide six pulse rectification of the $20 \mathrm{kHz}, \sim 140$ $\mathrm{kV}$ line-line voltages, resonant rectification techniques are used. Capacitors are placed in parallel with groups of rectification diodes. However, low loss; fast recovery diodes are still necessary for this design. 1,600 volt, 70 Amp ion implanted diodes manufactured by $I X Y S$ are used in the $140 \mathrm{kV}$ modulator assemblies. The circuit effect of the added rectification capacitance is that it acts like the transformer shunt peaking capacitors and must be considered in the analysis of the transformer tuning. The resonant rectification capacitors have the desirous effect to remove switching transients and "Miller" (ground) capacitance from the diodes. The Miller capacitance (to ground) can cause significant over-voltage of diodes high in the stack. The resonant rectification capacitors effectively swamp this failure mode. The resonant rectification capacitors are manufactured by General Atomics Energy Products and must have good tolerances, small size, and low equivalent series resistance and dissipation factor.

\section{Output Filtering}

Output filtering is provided by a standard "Pi-R" network. The input resistance helps mitigate ringing of the rectifier circuits. Filter capacitance values are chosen to provide adequate filtering yet minimize stored energy. The stored energy is wasted power that is lost at the end of the klystron pulse. With $120 \mathrm{kHz}$ ripple frequency, high efficiency with good filtering can be attained. 


\section{EQUIPMENT CONTROL RACK}

The operator and control room interface for the converter-modulator is via the equipment control rack. This rack controls and monitors all the power conditioning functions of the converter-modulator system such as the SCR controller, capacitor banks, IGBT switching network, oil tank assembly, and output load parameters. The rack includes functions for (Ethernet) "EPICS" based control I/O, Allen-Bradley PLC with local $\mathrm{I} / \mathrm{O}$ and station keeping, fast electronic monitors, and controls. This includes personnel protection interlocks as well as all electronic fault protection systems. The fault protection systems have the appropriate thru-put delays and latching functions to minimize the probability of equipment damage. The Digital Signal Processor (DSP) based control system has adaptive feedforward and feedback networks with learning algorithms to generate regulated modulator output pulses. With Pulse Width Modulation (PWM) of the individual IGBT pulses, the output waveforms can be compensated for capacitor bank droop and network overshoot. Figure 6 shows the modulator output at $80 \mathrm{kV}$ without adaptive controls and Figure 7 shows the $80 \mathrm{kV}$ output with adaptive controls. The complete equipment control rack is manufactured by Z-TEC Inc. located in Albuquerque, NM. We have not operated at full average power with the DSP controls. This has been more related to scheduling than actual implementation.

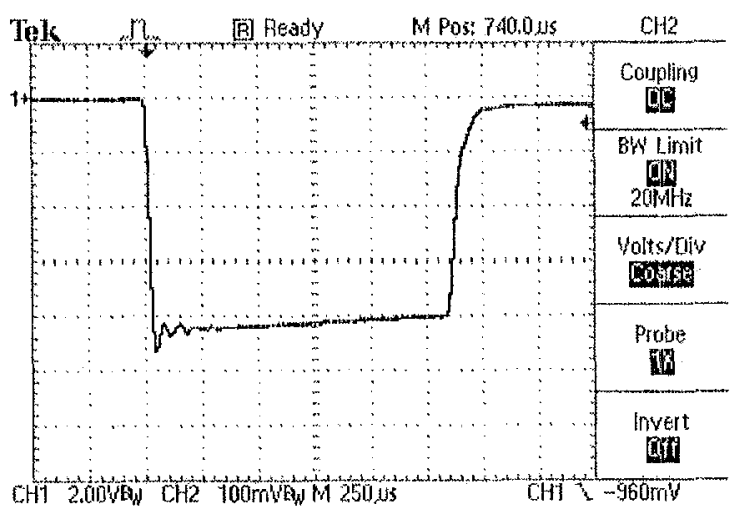

Figure 6: 80kV Output Pulse, 20kV/Division

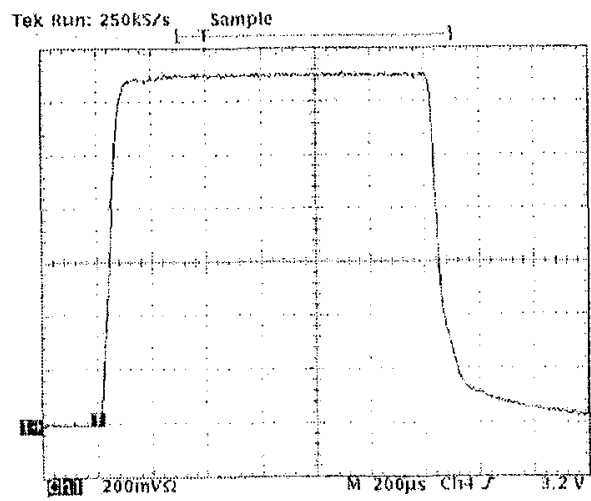

Figure 7: 80kV Output with Adaptive Feedforward/Feedback

\section{OPERATIONAL, RESULTS AND EFFICIENCY}

Operations at full average power were achieved within a week of the installation of the high-power $5 \mathrm{MW}, 805$ $\mathrm{MHz}$ Thales klystron. Figure 8 shows the output with 136 $\mathrm{kV}$ at the end of the pulse. We have operated the system to the limit of all our present loads, $130 \mathrm{kV}$ at $\sim 450 \mathrm{~kW}$ average power with the Marconi $2.5 \mathrm{MW}, 402 \mathrm{MHz}$ klystron and $\sim 800 \mathrm{~kW}$ average power at $136 \mathrm{kV}$ with the $5 \mathrm{MW}$ Thales $805 \mathrm{MHz}$ klystron. With the single 2.5 MW tube, tests interestingly had an electrical efficiency of only $\sim 88 \%$, with $\sim 3.7 \mathrm{~kW}$ loss per IGBT. Testing to the full $\sim 136 \mathrm{kV}$ output with the large $5 \mathrm{MW}, 805 \mathrm{MHz}$ Thales klystron $(\sim 800 \mathrm{~kW})$ gave IGBT losses of $\sim 1.7 \mathrm{~kW}$ each with an overall efficiency of $94 \%$. Operation at higher power provides a better match to the resonant converter and affords "zero-voltage-switching" of the IGBTs. Operations continue at the ORNL SNS accelerator. Start-up problems have been related to vendor $\mathrm{Q} / \mathrm{A}$ issues and are being worked as the convertermodulator production unfolds.

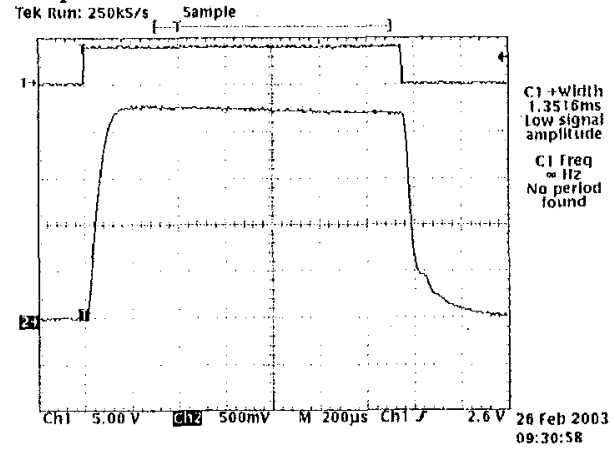

Figure 8: 136kV Output Pulse

\section{Crowbar Tests}

Extensive fault testing has also been performed with three times the anticipated SNS high-voltage cable length. These tests have been performed at voltages higher ( 145 kV) than anticipated in our operation. Figure 9 shows a $130 \mathrm{kV}$ crowbar test into a 5 joule wire. This test shows the result when the IGBT switching is disabled. Protection of the klystron is not dependant on the inhibit of IGBT switching and IGBT reliability is not dependant on interruption of gate drive during a klystron arc down.

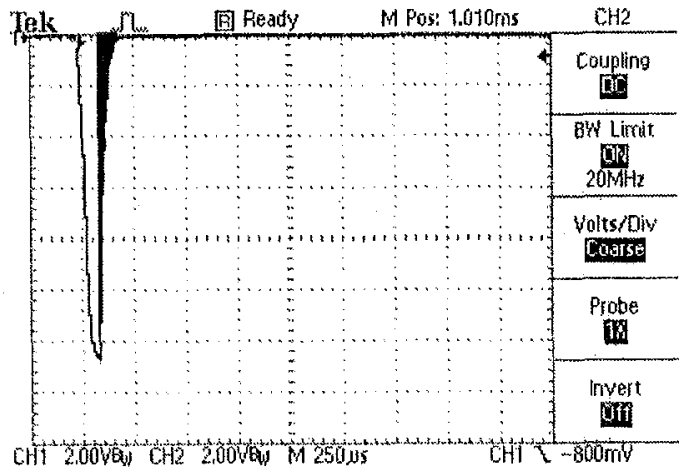

Figure 9: 130kV Self-Break Crowbar Test 
Figure 10 shows an arc-down event with the IGBT's continuing to switch, which did not fuse the test wire. In the shorted condition, the resonance of the convertermodulator is deQed, and little power transfer results. The low primary drive voltage coupled into the relatively high leakage inductance of the transformer does not even create an over-current situation for the IGBT's. This provides for a design that has fault ride-through capabilities. Future designs may not completely utilize fault sensing electronics. These results match our modeling.

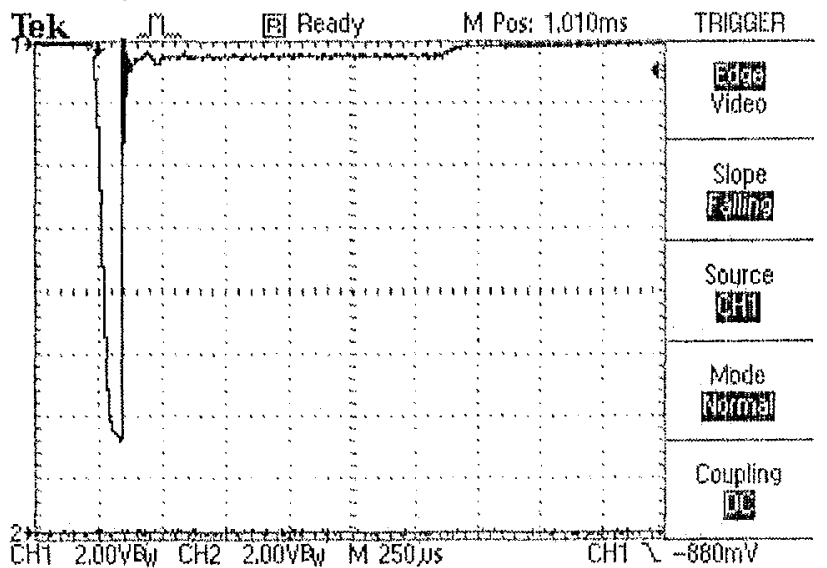

Figure 10: 130kV Run-On Fault Test

\section{CONCLUSION}

The polyphase resonant converter-modulator has demonstrated several new design methodologies that are expected to revolutionize long-pulse and "CW" modulator designs. These new technologies include special low inductance self-clearing capacitors, large amorphous nanocrystalline cut-core transformers, polyphase resonant voltage multiplication, resonant rectification, snubberless IGBT switching, and adaptive power supply control techniques. Design economies are achieved by the use of industrial traction components such as cast power transformers, IGBT's, and self-clearing capacitors. The compact and modular design minimizes on-site construction and a simplified utility interconnection scheme further reduces installation costs. The design does not require HV capacitor rooms and related crowbars. By generating high-voltage when needed, reliability and personnel safety is greatly enhanced. The system development to date has been completely successful and results indicate that operation to the full system average power (1.1 megawatts) should be achieved as required, within specification, when loads become available. 